\title{
Experiential Learning: A Definitive Edge In The Job Market
}

James Clark, Southern Arkansas University, USA

Gayle Webb White, Southern Arkansas University, USA

\begin{abstract}
The value of experiential learning is explored as it has now become a given among educators and corporate leaders that a university must provide experiential learning programs such as internships; real-life cases in marketing research, advertising, etc.; and voluntary student participation in income tax preparation for the needy and elderly; and many additional types of programs to promote the application of learning and involvement with the world of work. The paper presents one unique experiential learning program in complete detail-Student in Free Enterprise's Walgreens Wrangle. This is a twelve-university business strategy competition sponsored by the Students in Free Enterprise team at Southern Arkansas University that has the three-day involvement of managers of four major corporations. This period of time to interact both professionally and socially with a corporate group has proven to be invaluable to business majors and provided them with many experiential learning experiences.
\end{abstract}

Keywords: Experiential Learning, Applied Learning, Service Learning, Student Professional Development, Work Experience,

\section{INTRODUCTION}

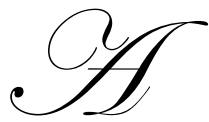

quality university business education program must include an experiential learning component. This experiential learning component can take many forms including internships of all types such as virtual, on-campus, and distance; service learning such as participation in the Voluntary Income Tax Assistance program, selling at the stores run by Goodwill, Clothes Closets, etc.; or classes that are involved with industries such as the marketing research class that does "real" research for clients, the advertising class that designs advertising for clients, or the computer classes that take on a project for a small business.

This interest in adding an experiential learning component has gathered reinforcement since the first university to be the recipient of the Malcolm Baldridge National Quality Award was the University of WisconsinStout where almost every student "graduates with related work experience" (Furst-Bowe and Wentz, 2006). Further reinforcement has been garnered when Nunamaker revealed that employers have become consistently more concerned about the professionalism of graduating students; experiential learning experiences help to address this issue of professionalism (Nunamaker, 2007). Further, Ann Turchi maintains that the quality of an MBA program should be judged by the professional network that the students build during the course of the program; she, too, believes that involvement with corporate managers is important (Turchi, 2007).

One recent year-long study of the education provided by business schools as reported by corporations in Silicon Valley revealed that "there are limits to what can be achieved in the traditional classroom setting . . .but there is still scope for more effective use of simulations and experiential learning to improve education in these dimensions" (Singh and Eischen, 2007).

As corporations have set higher requirements for professional development of graduates, several corporations have joined with universities to help fund various types of professional development endeavors, which, of course, include experiential learning. As an example, Jet Blue CEO, David Barger, offered \$5.4 million to the University of Michigan to endow an institute to develop leadership. This endowment will pay for many programs at 
the University of Michigan such as leadership development, internships, and will expose students to experiences that will help with their professional development (Maynard, 2007). "Motivated by the need for an improved labor force, businesses increasingly are working with schools in ways that can affect various aspects of the educational process" (Molseed, Adsup, and Voyles, 2003). Also, "there is an increasing recognition among graduates that they need work experience to get the jobs they want" (O"Keeffe and Hibbert, 2003). In fact, students often resort to volunteer work for non-profit organizations or to contract work in order to get experience industry demands (Anderson, 2008). Therefore, both industry and students realize how valuable experiential learning can be to their future success.

This paper addresses a unique experiential learning experience provided by the Students in Free Enterprise organization at Southern Arkansas University and is called Walgreens Wrangle, named for the Fortune 500 company who joined with the university in providing much of the funding for this annual event. The SIFE sponsor and the university faculty believe strongly that business and industry involvement in the educational programs of business students is vital for their professional development and for their future success; faculty strongly support the program by serving on judging panels and attending dinners with the executives.

\section{DESCRIPTION OF THE PROGRAM}

The Walgreen Wrangle program is a three-day event planned as a business competition among Students in Free Enterprise teams from around the country. For example, teams from the following universities were participants in the fall, 2008 Walgreen Wrangle: Louisiana State University, University of Arkansas, University of West Alabama, University of Alabama, University of Central Missouri, University of the Ozarks, West Texas A \& M, Texas Women's University, Kansas State University-Saline, John Brown University, and Northwest Arkansas Community College. Invitations are extended to approximately fifty universities annually; activities on their various campuses determine whether or not they can participate thus the universities will vary yearly. The group of teams were on our campus from October 16-18, 2008. Approximately $\$ 16,000$ was budgeted for the project and came from corporate sponsorships (Wright, 2008).

The teams were composed of six students; however, the team members could contact their SIFE members on their home campuses to gather data and to get much additional help with the case from members of their local business advisory boards. The three-day event began with a dinner with the students, representatives of the company that was the subject of the teams' study, and representatives from three corporate sponsors. The corporate sponsors who have worked with our students on the three competitions Southern Arkansas University has held include Walmart, Walgreens, Finish Line, Edward Jones, Schwans, Office Depot, Enterprise, Blue Beacon Truck Wash, and Sherwin Williams. Following the dinner, the executives from the company that was the focus for the competing teams spend several hours acquainting the team members with the history and culture of the company. The executives shared financial data, their vision of the future for their company and industry, and any opportunities and threats to their company's success as they perceived them to be. The students then asked questions for an hour or more. Following this time with the company representatives on Thursday afternoon and evening, the teams retired to their hotel rooms and began to work on the case. This work continued all day on Friday with the competition among the teams scheduled for Saturday morning.

These twelve SIFE teams were given thirty-six hours to develop an action plan to address the future of the company under study. At the Southern Arkansas University College of Business on Saturday morning, each team then presented their plans and new ideas to the company and to the corporate sponsors of the event who included representatives from Walgreens, Schwans, Finish Line, Sherwin-Williams, and Edward Jones for this particular competition. All of the university facilities in the College of Business were made available; all presentation rooms were equipped with technology allowing for power-point presentations of ideas. Scanning and copying equipment was made available for the design of brochures, advertisements, or other items the students needed for their presentations. The presentations were timed and were limited to 24 minutes. Recruiters from three sponsoring companies (Walgreens, Finish Line, and Schwans) served as mentors during the student team planning sessions and later judged the competition, thus, giving three days of their time and expertise to our students. In various annual competitions, different corporate sponsors participate; a minimum of three participate annually. This is the major value of the project; our students have representatives from four corporations (the company of the focus and 
three additional corporate sponsors) on campus for three days and have much time to interact both professionally and socially. Much experiential learning takes place over the course of the three days, the students add many names to their networks of professionals, and the corporations have an opportunity to see some of the best students the university has to offer. One human resource management professional who works for Finish Line heard about the event at the Career Day held on our campus on Wednesday before the Walgreen Wrangle and asked to come to the presentation ceremony so that she could meet these top students who were involved in the SIFE activity. This HRM professional maintained that this was an excellent way to recruit for her company who needed many additional managers for the many stores that were in the planning stage (Finish Line Interview, 2007).

The final event was the luncheon and presentation ceremony where the winners were announced and the cash awards were presented. First place team winner received $\$ 1200$, second place received $\$ 900$, third place received $\$ 600$, and fourth place received $\$ 300$.

\section{SPECIFIC VALUE TO SAU UNIVERSITY STUDENTS}

As hosts for the twelve SIFE teams, our Southern Arkansas University business students met during the teams' planning and strategy sessions, heard the teams' corporate presentations, and were totally involved with the event. As hosts, our SIFE students did not have a team in the competition thus freeing them to be in multi-sessions with corporate leaders and students from the various universities. Our students served as time-keepers, hosts for the competitions, and in numerous other capacities. They served as table hosts at the dinners and luncheons, the ice cream social, and the awards banquet and, thus, had many opportunities to visit with representatives from the four corporations involved. In addition, much of the material covered in classes is reinforced. In fact, when the student chairman for the event was specifically asked to name the most valuable lesson he had learned, he replied without any hesitation that it was budgeting. He had received quotes from hotels and food service vendors weeks before the event only to find out that the prices had risen when reservations were made (Wright, 2008). The knowledge gained from the preparation for this event and from these representatives of four major corporations was invaluable.

\section{RESULTS OF THE COMPETITION}

The first corporation to be studied in the Walgreens Wrangle competition was Southern Aluminum, a national manufacturer of aluminum desks, tables, and platforms. This was done in the fall of 2006. The results of this first Walgreens Wrangle was that Southern Aluminum implemented the new website design proposed, the new marketing campaign for the hospitality segment, and the new trade show booth/promotion strategy. Additionally, over 200 SIFE students had an opportunity to acquire job and internship offers; twenty offers were made to students (SIFE: Changing the World, 2007). In addition, "Wrangle provided a variety of social events which were wonderful opportunities for team members to interact with business people" (SIFE: As We Built Stepping Stones, We Became Stepping Stones, 2008).

Rodney D. Young Insurance Company was the focus of the 2007 Walgreens Wrangle. The company implemented two primary suggestions from the SIFE teams at Wrangle. RDY chose to focus on a single brand in their future expansion, as advocated by a number of teams at Wrangle. As suggested, they chose "National Insurance" from among the nine brands they currently support. National Insurance was selected by the competing teams as being the most appropriate for the firm's Hispanic customers. The company is also painting the exterior of new locations in the orange, white, and green of the Mexican flag. These suggestions have been well received by both new and current customers during the first twelve months they have been implemented. While there are no plans to change the signage (branding) of older locations, the exteriors will be painted in orange, white and green, to match the newer locations.

The focus of the third Walgreens Wrangle was Schwans and was held during the fall semester of 2008. The company was primarily seeking new and creative ways to reach out to a set of target customers their market research had recently identified. The Schwans' management team who participated in Wrangle was particularly taken with a set of ideas targeted at implementing home parties which would feature Schwans products. The Schwans team was so impressed with this set of ideas that they invited one of the SIFE team competitors from 
Wrangle to visit their home office to present the concepts to a larger management group. The new ideas, which were first presented in the fall of 2008 , are presently being tested in several markets.

\section{CONCLUSION AND RECOMMENDATIONS}

The three corporations that have been the focus of Wrangles--Southern Aluminum, Rodney D. Young Insurance Company, and Schwan--have all used the ideas generated by the university teams participating. Thus, they see the quality of the business students from these selected universities. The value to the students is the list of mentors and networks they build, the interview opportunities they receive from participating companies, and the opportunity to apply the knowledge they are learning in classes. Indeed, if there were truly a win-win situation, this would be that situation.

It does, however, take dedicated, quality faculty for the program to work. Also, budgeting the event continues to be problematic. Once there are successes, fund raising from corporations becomes a little easier. However, the authors recommend that administrators budget this item as it can bring great publicity to a university and future endowments.

\section{REFERENCES}

1. Anderson, Wayne, "IT for Free: Volunteering Today," Certification Magazine, certmag.com November, 2008, 50-53.

2. Finish Line Interview, 2007, Luncheon interview with human resource recruiter at the Awards Luncheon for SIFE's Walgreen Wrangle, October 18, 2007.

3. Furst-Bowe, Julie and Wentz, Meridith, "Beyond Baldridge," University Business.com, October, 2006, 4548.

4. Maynard, Micheline, "Hail to the Victors of \$5.4 Million," New York Times, Vol. CLVI, (53950), May 20, 2007, Section 3, 2-3.

5. Molseed, Timothy R., John Alsup, and James Voyles, "The Role of the Employee in Shaping Students' Work-Related Skills," Journal of Employment Counseling, Vol. CX, December, 2003, pp. 161-171.

6. Nunamaker, Troy D., "Employers and Student Candidates: How They See Each Other," NACE Journal, Vol. LXVII, (4), May, 2007, 26-31.

7. O'Keeffe, Alice and Katherine Hibbert, "Work Experience: For Whose Benefit?" New Statesman, Vol. CXXXII, (4662), November 3, 2003, 4 pages.

8. SAU/SIFE, "Objective 2: Entrepreneurial Development," SIFE: Changing the World, 2007, 3.

9. SAU/SIFE, “Criterion 3: Entrepreneurship,” SIFE: As We Built Stepping Stones, We Became Stepping Stones, 2008, 3.

10. Singh, Nirvikar and Kyle Eischen, "Lost, Dysfunctional or Evolving? A View of Business Schools from Silicon Valley," IMB Management Review, September, 2007, 320-344.

11. Turchi, Anne, "Playing Red Light, Green Light With the Man," Business Week Online.

12. Wright, Weston, Interview with the Co-ordinating Chairman of Walgreen Wrangle for 2008, December 11, 2008. 